\title{
Thermodynamic Treatment of Solid/Liquid Equilibrium Distribution Coefficients of Solutes in Multi-component Iron Alloys*
}

\author{
By Zen-ichiro MORITA, ,* Toshihiro TANAKA,** Norio IMAI,*** \\ Akihito KIYOSE**** and Yoshihiko KATAYAMA***
}

\begin{abstract}
Synopsis
In this work, the thermodynamic treatment of the equilibrium distribution coefficient $k_{\circ}^{X}$ in iron base ternary alloys described in the previous work $^{1,2)}$ was developed for iron base multi-component alloys and the effects of solute-interactions on the equilibrium distribution coefficient in multicomponent iron alloys were discussed thermodynamically. A new parameter for the evaluation of such effects was introduced. Furthermore, the equilibrium distribution coefficients of $\mathrm{Cr}, \mathrm{Ni}, \mathrm{Si}, \mathrm{Mn}$ and $\mathrm{Mo}$ at various compositions in $\mathrm{Fe}-\mathrm{Cr}-\mathrm{Ni}$ base alloys were measured. Small dependence of $k_{\circ}^{X}$ of those elements on the concentrations of $\mathrm{Cr}$ and $\mathrm{Ni}$ in those alloys was found and those results were explained by the application of new parameter.
\end{abstract}

Key words: equilibrium distribution coefficient; multi-component iron alloy; thermodynamics.

\section{Introduction}

Information on the equilibrium distribution coefficients of solute elements between solid and liquid phases is indispensable for the analysis of micro-segregation of elements during solidification of iron alloys. The values of the equilibrium distribution coefficients of solute elements in multi-component iron alloys seem to be different from the ones obtained from their binary phase diagrams because of the solute-interactions. The influence of solute-interactions on $k_{\circ}^{x}$, however, has not so far been elucidated thoroughly. In the previous work, ${ }^{1,2)}$ the authors derived the thermodynamic equation for the change in equilibrium distribution coefficient with the solute-interaction in the iron base ternary system and discussed the influence of solute-interactions on the equilibrium distribution of some elements in the $\mathrm{Fe}-\mathrm{C}, \mathrm{Fe}-\mathrm{N}, \mathrm{Fe}-\mathrm{H}$, $\mathrm{Fe}-\mathrm{P}$ and $\mathrm{Fe}-\mathrm{S}$ base ternary systems.

The purpose of this work is to develop the thermodynamic treatments of $k_{\circ}^{x}$ in the above iron base ternary systems for those in iron base multi-component alloys. Furthermore, the equilibrium distribution coefficients of some elements in $\mathrm{Fe}-\mathrm{Cr}-\mathrm{Ni}$ base alloys were investigated experimentally and the effects of solute-interactions on the equilibrium distribution of those elements were discussed thermodynamically.

\section{Thermodynamics of the Equilibrium Distri- bution Coefficients of Solute Elements in Multi-component Iron Alloys}

The equilibrium distribution coefficient $k_{\circ}^{x}$ is given thermodynamically in the previous work. ${ }^{1,2}$

$$
\begin{aligned}
& \ln k_{\circ}^{X}=\left(\dot{\mu}_{X}^{L}-\dot{\mu}_{X}^{S}\right) / R T+\left(\Delta \bar{G}_{X}^{E x, L}-\Delta \bar{G}_{X}^{E x, S}\right) / R T \\
& =\left(\dot{\mu}_{X}^{L}-\dot{\mu}_{X}^{S}\right) / R T+\ln \gamma_{X}^{L}-\ln \gamma_{X}^{S}
\end{aligned}
$$

where, $\dot{\mu}_{X}^{L}-\dot{\mu}_{X}^{S}$ : free energy of fusion of pure element $X$

$\Delta \bar{G}_{X}^{E x}:$ partial molar excess free energy of solute $X$

$\gamma_{X}:$ activity coefficient of solute $X$

$R$ : gas constant

$T$ : absolute temperature

Superscripts $L$ and $S$ : liquid and solid phases, respectively.

In order to calculate $k_{\circ}^{x}$ in multi-component alloys, the activity coefficient $\gamma_{X}$ should be rewritten in terms of interaction parameter in the same way that described in the previous works. ${ }^{1,2}$ Therefore, the effects of solute elements $X, Y, Z, \ldots$ on $\ln \gamma_{X}$ have to be taken into account in this work as follows.

$$
\ln \gamma_{X}=\ln \dot{\gamma}_{X}+\varepsilon_{X}^{X} \mathcal{N}_{X}+\varepsilon_{X}^{Y} \mathcal{N}_{Y}+\varepsilon_{X}^{Z} \mathcal{N}_{Z}+\cdots \cdots
$$

where, $\mathcal{N}_{X}$ : mole fraction of solute $X$

$\dot{\gamma}_{X}:$ activity coefficient of solute $X$ in infinite dilution

$\varepsilon_{X}^{X}: \quad$ self-interaction parameter of $X$

$\varepsilon_{X}^{Y}, \varepsilon_{X}^{Z}, \ldots:$ interaction parameter of $Y, Z, \ldots$ on $X$.

When $\ln \gamma_{x}^{L}$ and $\ln \gamma_{x}^{S}$ calculated from Eq. (2) are substituted in Eq. (1), the equilibrium distribution coefficient of solute element $X$ in multi-component iron alloy $k_{0}^{X, M}$ ( $M$ : multi-component) can be obtained from Eq. (3).

$$
\begin{aligned}
\ln k_{\circ}^{X, M}= & \left(\dot{\mu}_{X}^{L}-\dot{\mu}_{X}^{S}\right)+\ln \left(\dot{\gamma}_{X}^{L} / \dot{\gamma}_{X}^{S}\right) \\
& +\left(\varepsilon_{X}^{X}, L-\varepsilon_{X}^{X, S} k_{\circ}^{X, M}\right) \mathcal{N}_{X}^{L}+\left(\varepsilon_{X}^{X}, L-\varepsilon_{X}^{Y, s} k_{\circ}^{Y}, M\right) \mathcal{N}_{Y}^{L} \\
& +\left(\varepsilon_{X}^{Z}, L-\varepsilon_{X}^{Z, S} k_{\circ}^{Z, M}\right) \mathcal{N}_{Z}^{L}+\cdots \ldots \ldots \ldots \ldots \ldots \ldots . .
\end{aligned}
$$

On the other hand, the equilibrium distribution coefficient of solute $X$ in binary iron alloy, $k_{0}^{X, 2}$, is given by Eq. (4) since $\mathcal{N}_{Y}^{L}, \mathcal{N}_{Z}^{L}$, etc. are equal to zero in Eq. (3) for binary iron alloys.

$$
\begin{aligned}
\ln k_{\circ}^{X, 2}= & \left(\dot{\mu}_{X}^{L}-\dot{\mu}_{X}^{S}\right)+\ln \left(\dot{\gamma}_{X}^{L} / \dot{\gamma}_{X}^{S}\right) \\
& +\left(\varepsilon_{X}^{X}, L-\varepsilon_{X}^{X}, k_{\circ}^{X}, 2\right) \mathcal{N}_{X}^{L}
\end{aligned}
$$

As the third term of Eqs. (3) and (4) has a little contribution to $k_{\circ}^{x}$ in both binary and multi-compo-

\footnotetext{
* $\quad$ Based on the paper presented to the 112th ISIJ Meeting, October 1986, S1061, at Nagoya University in Nagoya. Manuscript received on August 31, 1987; accepted in the final form on December 11, 1987. (C) 1988 ISIJ

** Department of Metallurgical Engineering, Faculty of Engineering, Osaka University, Yamadaoka, Suita 565.

*** Graduate School, Osaka University.

**** Formerly Graduate School, Osaka University. Now at R \& D Laboratories-III, Nippon Steel Corporation, Edamitsu, Yahatahigashi-ku, Kitakyushu 805.
} 
nent iron alloys, ${ }^{11}$ the right-hand side of Eq. (4) becomes to be nearly equal to the parts from the first to the third term in the right-hand side of Eq. (3). Then, the following equation is obtained.

$$
\begin{aligned}
\ln & \left(k_{\circ}^{X, M} / k_{\circ}^{X, 2}\right) \\
& =\left(\varepsilon_{X}^{Y, L}-\varepsilon_{X}^{Y, S} k_{\circ}^{Y, M}\right) \mathcal{N}_{Y}^{L}+\left(\varepsilon_{X}^{Z, L}-\varepsilon_{X}^{Z, S} k_{\circ}^{Z, M}\right) \mathcal{N}_{Z}^{L}+\cdots \cdots \\
& =\left(1-m k_{\circ}^{Y, M}\right) \varepsilon_{X}^{Y, L} \mathcal{N}_{Y}^{L}+\left(1-m^{\prime} k_{\circ}^{Z, M}\right) \varepsilon_{X}^{Z, L} \mathcal{N}_{Z}^{L}+\cdots \cdots \\
& =\sum\left(1-m k_{\circ}^{Y, M}\right) \varepsilon_{X}^{Y, L} \mathcal{N}_{Y}^{L} \quad \ldots \ldots \ldots \ldots \ldots \ldots \ldots \ldots \ldots
\end{aligned}
$$

where, $m=\varepsilon_{X}^{Y, S} / \varepsilon_{X}^{Y, L}$

$$
m^{\prime}=\varepsilon_{X}^{Z}, s / \varepsilon_{X}^{Z}, L, \cdots \cdots .
$$

The left-hand side of Eq. (5) shows the ratio of the equilibrium distribution coefficient of solute $X$ in multi-component iron alloy to that in binary alloy, and this ratio means the change in equilibrium distribution coefficient of solute $X$ by the addition of alloying elements $Y, Z, \ldots$ to the binary alloy. That is, the ratio $k_{\circ}^{X, M} / k_{\circ}^{X, 2}$ indicates the effect of soluteinteraction on $k_{\circ}^{x}$ in multi-component iron alloy. Therefore, the authors defined this ratio as Distribution Interaction Coefficient (DIG) in the previous work. $^{2)} \quad$ For example, in case of the $\mathrm{Fe}-\mathrm{C}-X$ ternary system, the change in equilibrium distribution coefficient of solute element $X$ with the concentration of carbon is given as follows.

$$
\ln \left(k_{\circ}^{X, 3} / k_{\circ}^{X, 2}\right)=\left(1-m k_{\circ}^{\mathrm{C}, 3}\right) \varepsilon_{X}^{\mathrm{C}, L} \mathcal{N}_{\mathrm{C}}^{L}
$$

Figure 1 shows the change in $k_{0}^{x, 3} / k_{0}^{x, 2}$ of various elements in equilibrium of liquid and $\gamma$ phases with the concentration of carbon in $\mathrm{Fe}-\mathrm{C}-X$ ternary alloy. In this figure, the values of $k_{\circ}^{X, 3} / k_{\circ}^{X, 2}$ were obtained by dividing the experimental results ${ }^{1,3-8)}$ of $k_{\circ}^{x, 3}$ for $\mathrm{Fe}-\mathrm{G}-X$ ternary alloys by the values of $k_{\mathrm{o}}^{X, 2}$ listed in Table $1 .{ }^{9,10)}$ The dotted lines in Fig. 1 indicate the results calculated from Eq. (6) in case of $m=1$. The reason why the value of $m$ is equal to unity was discussed in details in the previous work. ${ }^{2)}$ The values of $\varepsilon_{X}^{\mathrm{C}, L}$ used in the present calculation of $k_{\mathrm{o}}^{X}, 3 / k_{\mathrm{o}}^{X}, 2$ are shown in Table 1. As the accuracy of the calculated results of $k_{\circ}^{X, 3} / k_{\circ}^{X, 2}$ is sensitive to that of $\varepsilon_{X}^{\mathrm{c}, L}$ the careful attention should be paid for the selection of the data on $\varepsilon_{X}^{\mathrm{C}, L}$. The values of $\varepsilon_{X}^{\mathrm{C}, L}$ recommended by the 19th Committee of the Japan Society for the Promotion of Science were used in the present work.

It is obvious from this figure that the relationship between $\ln \left(k_{\circ}^{X}, 3 / k_{\circ}^{X}, 2\right)$ and carbon concentration clearly shows the effect of carbon on $k_{\circ}^{x}$ of various elements in the $\mathrm{Fe}-\mathrm{C}-X$ ternary systems and also the calculated results are in good agreement with the experimental ones. In the right-hand side of Eq. (6), the value of $k_{\mathrm{o}}^{\mathrm{c}}$ is known to be nearly equal to $0.3 .^{9,10}$ For the elements with positive interaction for carbon, i.e., $\varepsilon_{X}^{\mathrm{C}},{ }^{L}>0$, for example $\mathrm{Sn}, \mathrm{Si}, \mathrm{Cu}, \mathrm{Ni}, \mathrm{Co},{ }^{11)}$ the value of the right-hand side of Eq. (6) is positive and this means that $k_{\circ}^{x}$ increases with increasing concentration of carbon. However, it is reversed for the elements having negative interaction for carbon, i.e., $\varepsilon_{X}^{\mathrm{C}, L}<0$, for example V, Gr, Mn. ${ }^{11)}$ Although the values of

\begin{tabular}{|c|c|c|c|c|}
\hline \multirow{2}{*}{ Elements } & \multicolumn{3}{|c|}{$k_{\circ}^{X}$} & \multirow{2}{*}{$\frac{\varepsilon_{X}^{\mathrm{C}, L}}{\text { Ref. 11) }}$} \\
\hline & Liquid- $\delta$ & Liquid- $\gamma$ & Ref. No. & \\
\hline Co & 0.94 & 0.95 & 9) & 0.99 \\
\hline $\mathrm{Cr}$ & 0.95 & 0.85 & 9) & -5.63 \\
\hline $\mathrm{Cu}$ & 0.90 & 0.70 & 9) & 3.26 \\
\hline $\mathrm{Mn}$ & 0.77 & 0.79 & 10) & -2.67 \\
\hline $\mathrm{Ni}$ & 0.83 & 0.95 & 9) & 1.58 \\
\hline $\mathrm{Si}$ & 0.83 & 0.50 & 9) & 8.90 \\
\hline $\mathrm{Sn}$ & 0.35 & 0.19 & 10) & 8.90 \\
\hline $\mathrm{V}$ & 0.93 & 0.63 & 10) & -6.92 \\
\hline
\end{tabular}
$k_{\circ}^{\mathrm{Si}, 3}$ are considerably different from those of $k_{\mathrm{o}}^{\mathrm{Sn}, 3}$ in
Table 1. Equilibrium distribution coefficients of solute elements in iron base binary alloys and interaction parameters of carbon on some solute elements in liquid iron alloys.

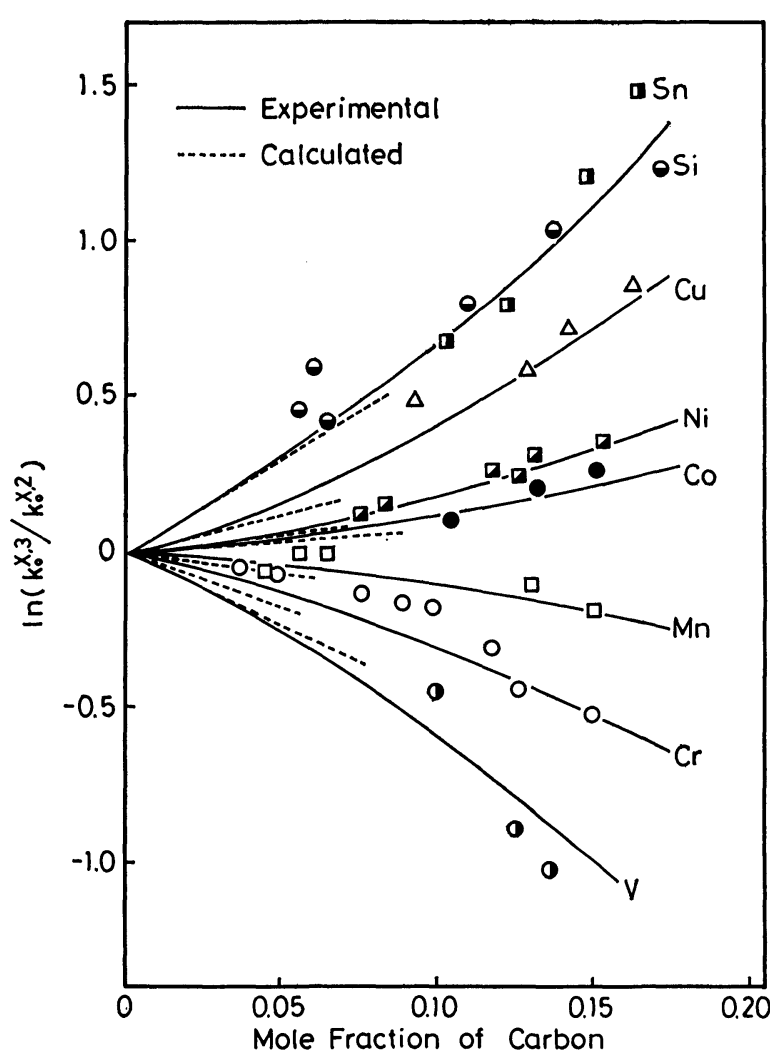

Experimental results

Si, Mn: Kagawa et al., ${ }^{5,6)}$ Umeda et al. $^{3)}$

Cr: Kagawa et al.,4) Ogilvy et al. ${ }^{71}$

$\mathrm{Ni}, \mathrm{V}, \mathrm{Sn}, \mathrm{Co}, \mathrm{Cu}:$ Morita et al..$^{1,8)}$

Fig. 1. Change in $\ln \left(k_{\circ}^{X, 3} / k_{\circ}^{X, 2}\right)$ of various elements with the concentration of carbon in $\mathrm{Fe}-\mathrm{C}$ base alloys.

$\mathrm{Fe}-\mathrm{C}$ base ternary alloys, ${ }^{6,8)}$ the values of $k_{\circ}^{\mathrm{si}, 3} / k_{\circ}^{\mathrm{si}, 2}$ are nearly equal to those of $k_{\mathrm{o}}^{\mathrm{Sn}, 3} / k_{\circ}^{\mathrm{Sn}, 2}$ as shown in Fig. 1. This corresponds to the fact that both $\varepsilon_{\mathrm{Si}}^{\mathrm{C}, L}$ and $\varepsilon_{\mathrm{Sn}}^{\mathrm{C}, L}$ in Table 1 show the same values, in other words, carbon has the same effect on $k_{0}^{\mathrm{si}, 3}$ and $k_{\mathrm{o}}^{\mathrm{sn}, 3}$ in $\mathrm{Fe}-\mathrm{C}$ base alloys.

On the basis of Eq. (6) or generally Eq. (5), it is possible to predict the effect of solute-interaction on the equilibrium distribution of solute element between solid and liquid phases in multi-component iron alloys. In particular, each term in the right- 
hand side of Eq. (5) shows the form of $\left(1-m k_{\circ}^{Y, M}\right) \varepsilon_{X}^{V}, L$, and the sign and the absolute value of this term for each alloying element will determine the effect of these elements on $k_{0}^{x}$. Therefore, the term (1$\left.m k_{\circ}^{Y, M}\right) \varepsilon_{X}^{Y}, L$ is considered as the important parameter for the evaluation of the effect of solute-interactions on $k_{\circ}^{x}$ in multi-component iron alloys. Then, the authors define the term $\left(1-m k_{\mathrm{o}}^{Y, M}\right) \varepsilon_{X}^{Y, L}$ as Distribution Interaction Parameter (DIP), $\delta_{X}^{Y}$.

$$
\delta_{X}^{Y}=\left(1-m k_{\circ}^{Y, M}\right) \varepsilon_{X}^{Y, L}
$$

Equation (5) can be rewritten by the use of [mass $\%$ ] as follows.

$$
\log \left(k_{\circ}^{X, M} / k_{\circ}^{X, 2}\right)=\Sigma\left(1-m k_{\circ}^{Y, M}\right) e_{X}^{Y, L}[\operatorname{mass} \% Y]^{L}
$$

where, $e_{X}^{Y, L}$ : interaction parameter of $Y$ on $X$.

For $\mathrm{Fe}-\mathrm{C}$ base ternary and quarternary alloys with high carbon concentration ( 4.3 mass $\% \mathrm{C})$, Kagawa et al. ${ }^{4-6)}$ calculated the equilibrium distribution coefficients of solute elements by the use of the equation similar to Eq. (3).

In this work, the equilibrium distribution of solute elements between solid and liquid phases in $\mathrm{Fe}-\mathrm{Cr}-\mathrm{Ni}$ base alloys, i.e., the fundamental systems of alloy steels, are discussed on the basis of Eq. (8) which clearly shows the relation between the change in $k_{0}^{x}$, namely $k_{\circ}^{X, w} / k_{\circ}^{X, 2}$ and the solute-interaction, $e_{X}^{Y, L}$ in multi-component iron alloy.

\section{Application of Distribution Interaction Pa- rameter for the Analysis of the Effect of Solute-interaction on $k_{\circ}^{x}$ in $\mathrm{Fe}-\mathrm{Cr}-\mathrm{Ni}$ Base Multi-component Iron Alloy}

In this work, the equilibrium distribution coeffi- cients of some elements in $\mathrm{Fe}-\mathrm{Cr}-\mathrm{Ni}$ base multi-component alloys were investigated experimentally by the two methods described below. Then, the effects of solute-interactions on $k_{\circ}^{x}$ of solute elements in those alloys were discussed by the application of DIP. The chemical compositions of the specimens are listed in Table 2.

\section{Experimental}

\section{Solid-Liquid Equilibrium}

Figure 2 shows the experimental apparatus. After the alumina cell containing the specimen was set in the furnace, the liquidus temperature was measured by the thermal analysis. Then, the specimen was held for about $24 \mathrm{~h}$ at the temperature of $5 \sim 10^{\circ} \mathrm{C}$ below the liquidus temperature at which the solid and liquid phases were coexisting. The specimen in the alumina cell was then quenched into water bath. After the specimen being cut and polished, the concentrations of the solute elements near the solid-liquid interface were measured by electron probe micro analyzer (EPMA) to determine $k_{\circ}^{x}$. The conditions adopted for the analysis were described in details in the previous reports. ${ }^{1,12}$

\section{Stationary Interface Method}

Some difficulties may arise in the above method because the difference between solidus and liquidus temperature is small in the iron corner of $\mathrm{Fe}-\mathrm{Cr}-\mathrm{Ni}$ base alloys. Therefore, the stationary interface method developed by Umeda et al. ${ }^{3,13)}$ for the determination of $k_{0}^{x}$ was adopted for those kinds of alloys. The alumina cell containing the specimen of $12 \mathrm{~cm}$ long was set in the furnace having a small temperature gradient as shown in Fig. 3. After the temperature gradient was controlled so as to melt only the upper

Table 2. Chemical compositions of the alloys and experimental results on the equilibrium distribution coefficients $k_{\circ}^{X}$ of

\begin{tabular}{|c|c|c|c|c|c|c|c|c|c|c|}
\hline \multicolumn{5}{|c|}{ Compositions (mass\%) } & \multirow{2}{*}{$\begin{array}{c}\text { Solid } \\
\text { phase }\end{array}$} & \multirow{2}{*}{$k_{\circ}^{\mathrm{Cr}}$} & \multirow{2}{*}{$k_{\mathrm{o}}^{\mathrm{Ni}}$} & \multirow{2}{*}{$k_{\circ}^{\mathrm{Si}}$} & \multirow{2}{*}{$k_{\circ}^{\mathrm{Mn}}$} & \multirow{2}{*}{$k_{\mathrm{o}}^{\mathrm{Mo}}$} \\
\hline $\mathrm{Cr}$ & $\mathrm{Ni}$ & $\mathrm{Si}$ & $\mathrm{Mn}$ & Mo & & & & & & \\
\hline 3.16 & 3.16 & 1.08 & & & $\delta$ & 0.93 & 0.80 & 0.79 & & \\
\hline 4.89 & 1.42 & 0.54 & & & $\delta$ & 0.96 & 0.78 & 0.79 & & \\
\hline 5.00 & 4.95 & 0.51 & & & $\delta$ & 0.94 & 0.78 & 0.76 & & \\
\hline 10.26 & 5.08 & 0.52 & & & $\delta$ & 0.97 & 0.78 & 0.80 & & \\
\hline 18.14 & 8.13 & 0.84 & 0.82 & 0.84 & $\delta$ & 0.95 & 0.77 & 0.78 & 0.81 & 0.84 \\
\hline 3.09 & 3.02 & & 1.01 & & $\delta$ & 0.96 & 0.79 & & 0.81 & \\
\hline 4.99 & 5.07 & & 0.54 & & $\delta$ & 0.96 & 0.79 & & 0.76 & \\
\hline 2.98 & 2.99 & & & 1.04 & $\delta$ & 0.94 & 0.81 & & & 0.85 \\
\hline 5.02 & 4.85 & & & 0.51 & $\delta$ & 0.95 & 0.80 & & & 0.80 \\
\hline 2.94 & 9.89 & 0.99 & & & $\gamma$ & 0.97 & 1.00 & 0.76 & & \\
\hline 4.98 & 10.38 & 0.52 & & & $\gamma$ & 0.95 & 0.94 & 0.72 & & \\
\hline 5.00 & 15.01 & 0.52 & & & $\gamma$ & 0.94 & 0.92 & 0.69 & & \\
\hline 5.08 & 9.99 & & 0.56 & & $\gamma$ & 0.94 & 0.91 & & 0.83 & \\
\hline 5.03 & 9.63 & & & 0.51 & $r$ & 0.93 & 0.92 & & & 0.71 \\
\hline 4.96 & 15.00 & & 0.98 & 0.98 & $r$ & 0.94 & 0.94 & & 0.76 & 0.67 \\
\hline 9.61 & 10.32 & & 0.91 & 0.99 & $\gamma$ & 0.94 & 0.92 & & 0.80 & 0.63 \\
\hline 9.65 & 24.13 & 1.09 & 0.88 & 0.98 & $\gamma$ & 0.96 & 0.94 & 0.61 & 0.72 & 0.68 \\
\hline 9.81 & 38.42 & 1.24 & 1.19 & 0.92 & $r$ & 0.97 & 0.96 & 0.57 & 0.66 & 0.75 \\
\hline 20.14 & 24.00 & 1.26 & 1.00 & 0.99 & $\gamma$ & 0.97 & 0.95 & 0.69 & 0.74 & 0.67 \\
\hline 19.40 & 38.70 & 1.24 & 1.09 & 0.91 & $\gamma$ & 0.97 & 0.98 & 0.57 & 0.74 & 0.71 \\
\hline
\end{tabular}
$\mathrm{Cr}, \mathrm{Ni}, \mathrm{Si}, \mathrm{Mn}$ and $\mathrm{Mo}$ in $\mathrm{Fe}-\mathrm{Cr}-\mathrm{Ni}$ base alloys. 
part of the rod specimen, it was held for $3 \mathrm{~h}$. Then, the specimen in the alumina cell was quenched into water bath to fix the solid-liquid interface. From the preliminary experiment, it was confirmed that the plain solid-liquid interface could be obtained after being held at that temperature for $3 \mathrm{~h}$. Then, as stated in Sec. III. 1. 1, $k_{\circ}^{x}$ was determined by EPMA analysis.

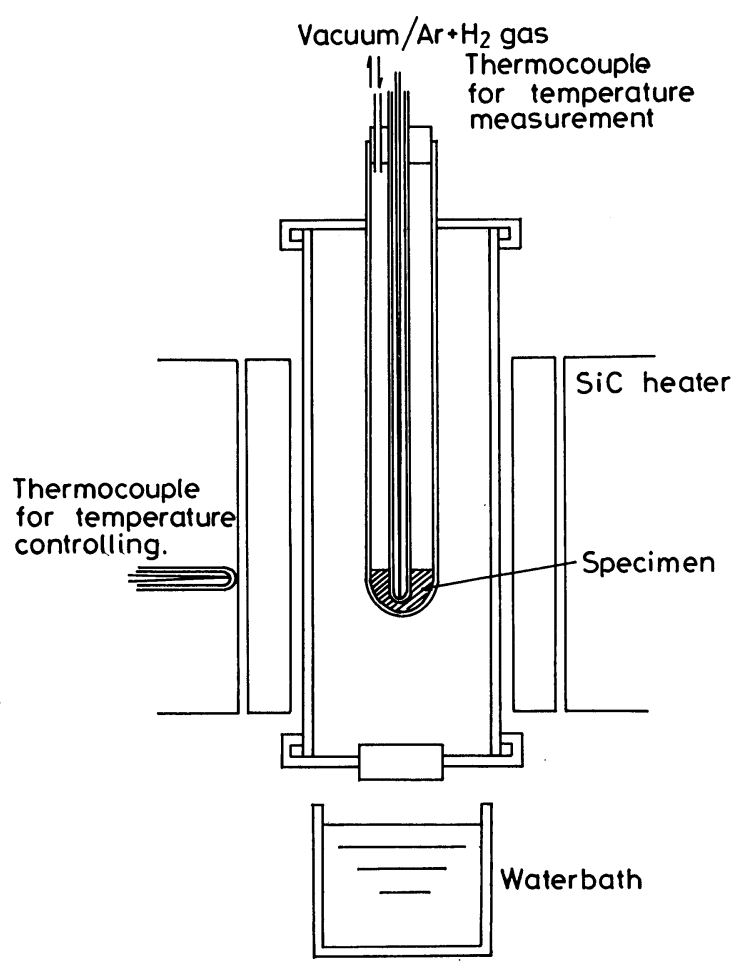

Fig. 2. Apparatus for the solid-liquid equilibrium experiment.

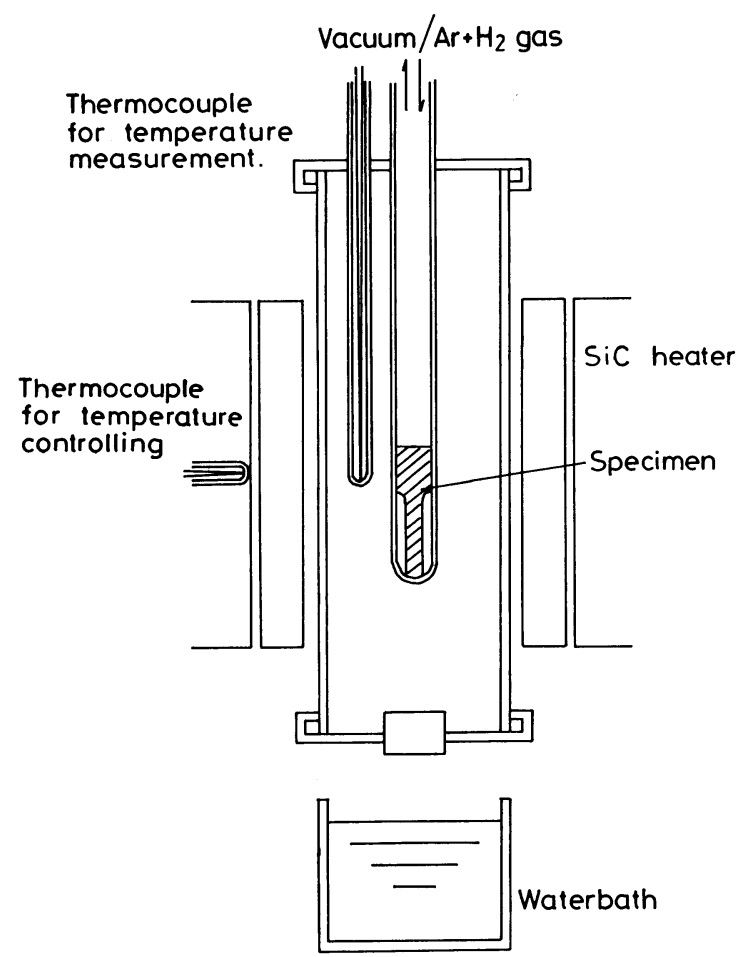

Fig. 3. Experimental apparatus for the stationary interface method.

\section{Results and Discussion}

Table 2 represents the experimental results of $k_{\circ}^{X}$ of $\mathrm{Cr}, \mathrm{Ni}, \mathrm{Si}, \mathrm{Mn}$ and $\mathrm{Mo}$ in $\mathrm{Fe}-\mathrm{Cr}-\mathrm{Ni}$ base alloys and Figs. 4 to 8 show those results together with the values reported by other investigators. ${ }^{13-18)}$ Some experimental results on $k_{\circ}^{x}$ of $\mathrm{Si}, \mathrm{Mn}$ and Mo shown in Table 2 were obtained for the different specimens with almost the same $\mathrm{Gr}$ and $\mathrm{Ni}$ concentrations. Therefore, some values of $k_{\circ}^{\mathrm{cr}}$ and $k_{\circ}^{\mathrm{Ni}}$ in Figs. 4 and 5 are the average of the experimental results for those different specimens shown in Table 2. The depen-

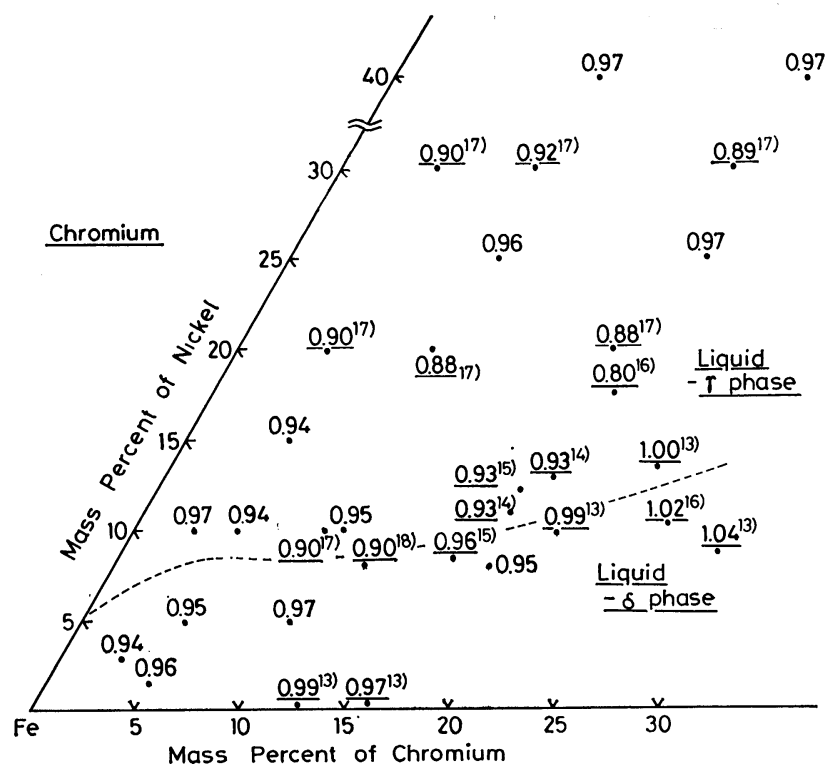

Values with underline: the results reported by other investigators $^{13-18)}$

Fig. 4. Equilibrium distribution coefficient of $\mathrm{Cr}$ in $\mathrm{Fe}-\mathrm{Cr}-$ Ni base alloys.

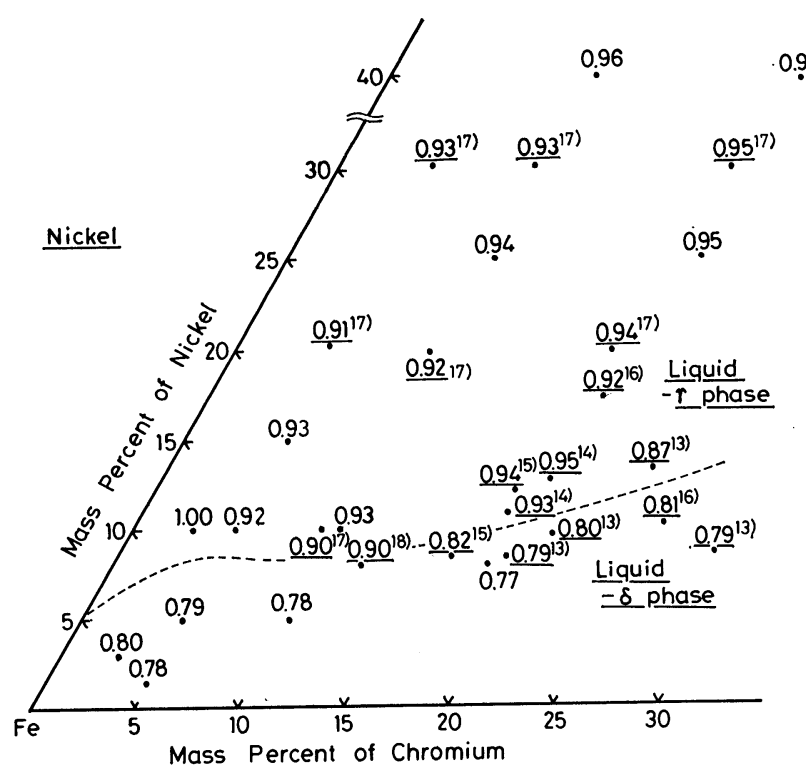

Values with underline: the results reported by other investigators ${ }^{13-18)}$

Fig. 5. Equilibrium distribution coefficient of $\mathrm{Ni}$ in $\mathrm{Fe}-\mathrm{Cr}-$ Ni base alloys. 


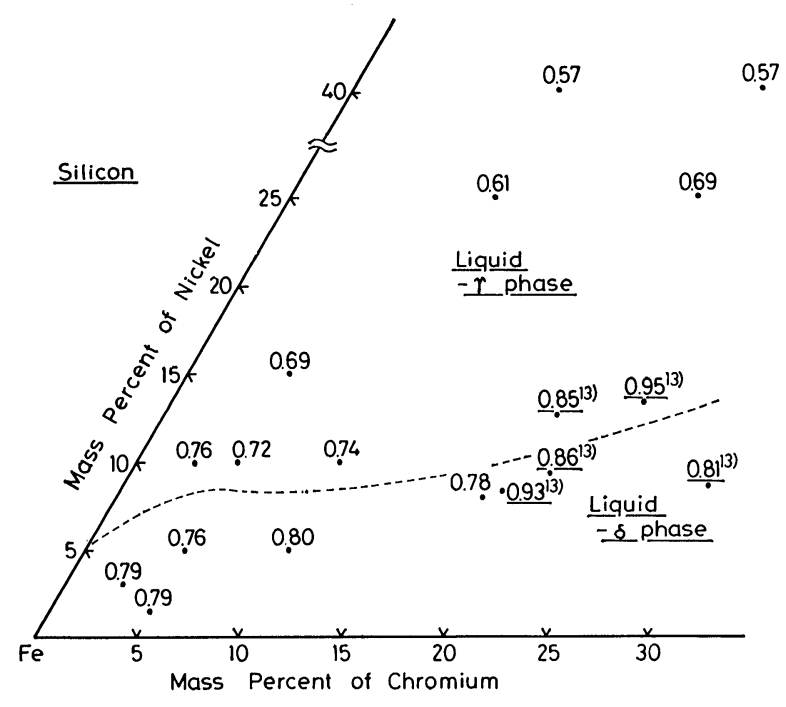

Values with underline: the results reported by Yamada et al. ${ }^{13)}$

Fig. 6. Equilibrium distribution coefficient of $\mathrm{Si}$ in $\mathrm{Fe}-\mathrm{Cr}-$ Ni base alloys.

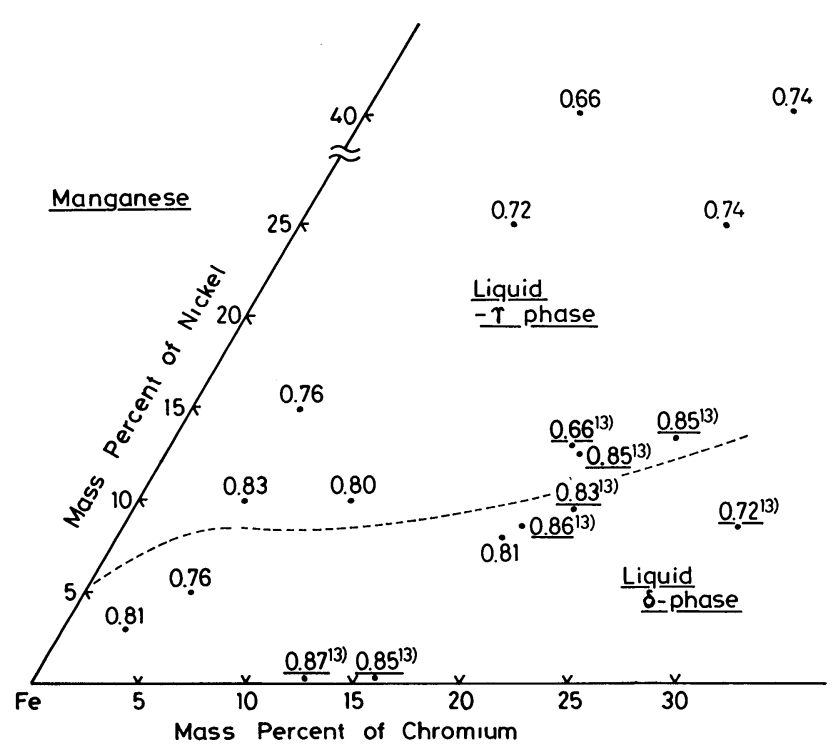

Values with underline: the results reported by Yamada et al. ${ }^{13)}$

Fig. 7. Equilibrium distribution coefficient of $\mathrm{Mn}$ in $\mathrm{Fe}-$ $\mathrm{Cr}-\mathrm{Ni}$ base alloys.

dence of $k_{\circ}^{x}$ of each element on the concentrations of $\mathrm{Ni}$ and $\mathrm{Cr}$ is very small in the equilibrium states of liquid and $\delta$ phases and of liquid and $\gamma$ phases. These results can be explained by means of DIP as described below. As an example for $\mathrm{Si}, \mathrm{Eq}$. (8) can be rewritten as Eq. (9).

$$
\begin{aligned}
& \log \left(k_{\circ}^{\mathrm{Si}, 4} / k_{\circ}^{\mathrm{Si}, 2}\right) \\
& =\left(1-m k_{\circ}^{\mathrm{Cr}, 4}\right) e_{\mathrm{Si}}^{\mathrm{Cr}, L}[\operatorname{mass} \% \mathrm{Cr}]^{L} \\
& \quad+\left(1-m^{\prime} k_{\circ}^{\mathrm{Ni}, 4}\right) e_{\mathrm{Si}}^{\mathrm{Ni}, L}[\operatorname{mass} \% \mathrm{Ni}]^{L}
\end{aligned}
$$

where the values ${ }^{11)}$ of $e_{\mathrm{Si}}^{\mathrm{Cr}}, L$ and $e_{\mathrm{S1}}^{\mathrm{N1}, L}$ are shown in Table 3 , and also $m=m^{\prime}=1$.

When the concentration of $\mathrm{Si}$ is low, $k_{\mathrm{o}}^{\mathrm{or}, 4}$ and

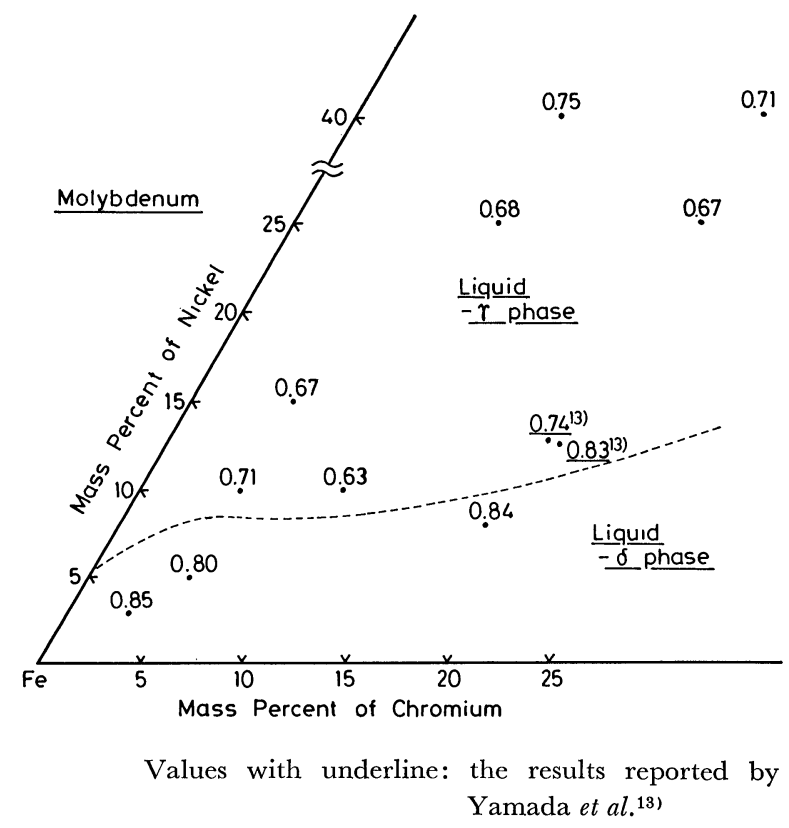

Fig. 8. Equilibrium distribution coefficient of $\mathrm{Mo}$ in $\mathrm{Fe}-$ $\mathrm{Cr}-\mathrm{Ni}$ base alloys.

Table 3. Interaction parameter used for the calculation of $k_{\circ}^{\mathrm{Si}, 4} / k_{\circ}^{\mathrm{Si}, 2}$ in $\mathrm{Fe}-\mathrm{Cr}-\mathrm{Ni}$ base and $\mathrm{Fe}-$ $\mathrm{Cr}-\mathrm{C}$ base alloys.

\begin{tabular}{ccc}
\hline$e_{\mathrm{Si}}^{\mathrm{Cr}, L}$ & -0.0003 & $-0.57 / T^{*}$ \\
$e_{\mathrm{Si}}^{\mathrm{Ni}, L}$ & $(1903 \mathrm{~K})$ & \\
$e_{\mathrm{Si}}^{\mathrm{g}}, L$ & 0.005 & $9.4 / T^{*}$ \\
\hline
\end{tabular}

* Temperature dependence estimated from the relation $e_{X}^{Y}, L_{\infty}$ $1 / T$.

$k_{\circ}^{\mathrm{N}, 4}$ may be regarded as $k_{\circ}^{\mathrm{Cr}, 3}$ and $k_{\circ}^{\mathrm{N}, 3}$ in the $\mathrm{Fe}-\mathrm{Cr}-$ $\mathrm{Ni}$ ternary system, respectively. In this work, the values of $k_{\circ}^{\mathrm{cr}, 3}$ and $k_{\circ}^{\mathrm{Ni}, 3}$ in $\mathrm{Fe}-\mathrm{Cr}-\mathrm{Ni}$ ternary alloys were calculated from the thermodynamic equations and data given by Yamada et al. ${ }^{19)}$ Figure 9 shows the calculated results of the dependence of $k_{\circ}^{\mathrm{si}, 4} / k_{\circ}^{\mathrm{si}, 2}$ on the concentrations of $\mathrm{Ni}$ and $\mathrm{Cr}$. In comparison with those of $\mathrm{Fe}-\mathrm{Cr}-\mathrm{Ni}$ base alloys, the calculated results of $k_{\circ}^{\mathrm{si}, 4} / k_{\circ}^{\mathrm{si}, 2}$ at various concentrations of $\mathrm{G}$ and $\mathrm{Cr}$ in $\mathrm{Fe}-\mathrm{Cr}-\mathrm{C}$ base alloys are shown in Fig. 10. The equation similar to Eq. (9) can also be obtained for this alloy as shown below:

$$
\begin{aligned}
\log ( & \left(k_{\circ}^{\mathrm{si}, 4} / k_{\circ}^{\mathrm{si}, 2}\right) \\
= & \left(1-m k_{\circ}^{\mathrm{Cr}, 4}\right) e_{\mathrm{Si}}^{\mathrm{Cr}, L}[\mathrm{mass} \% \mathrm{Cr}]^{L} \\
& +\left(1-m^{\prime} k_{\circ}^{\mathrm{c}, 4}\right) e_{\mathrm{Si}}^{\mathrm{C}, L}[\text { mass } \% \mathrm{C}]^{L}
\end{aligned}
$$

where the values ${ }^{11)}$ of $e_{\mathrm{Si}}^{\mathrm{Cr}, L}$ and $e_{\mathrm{Si}}^{\mathrm{C}}{ }^{L}$ are indicated in Table 3 , and the values of $k_{\circ}^{\mathrm{cr}, 3}$ and $k_{\circ}^{\mathrm{c}, 3}$ in $\mathrm{Fe}-\mathrm{Cr}-\mathrm{C}$ ternary alloys calculated by Kundrat et al. ${ }^{20)}$ were used for the values of $k_{\circ}^{\mathrm{cr}, 4}$ and $k_{\circ}^{\mathrm{c}, 4}$.

As can be seen from Fig. 9, the change in $k_{\mathrm{o}}^{\mathrm{si}}$ with the concentrations of $\mathrm{Cr}$ and $\mathrm{Ni}$ in $\mathrm{Fe}-\mathrm{Cr}-\mathrm{Ni}$ base alloys is very small. This conclusion is in good agreement with the results obtained by the above experiments. On the other hand, the dependence of $k_{0}^{\mathrm{si}}$ on 
Fig. 9.

Change in $k_{\circ}^{\mathrm{Si}, 4} / k_{\mathrm{o}}^{\mathrm{Si}, 2}$ with the concentrations of $\mathrm{Cr}$ and $\mathrm{Ni}$ in $\mathrm{Fe}-\mathrm{Cr}-\mathrm{Ni}$ base alloys.
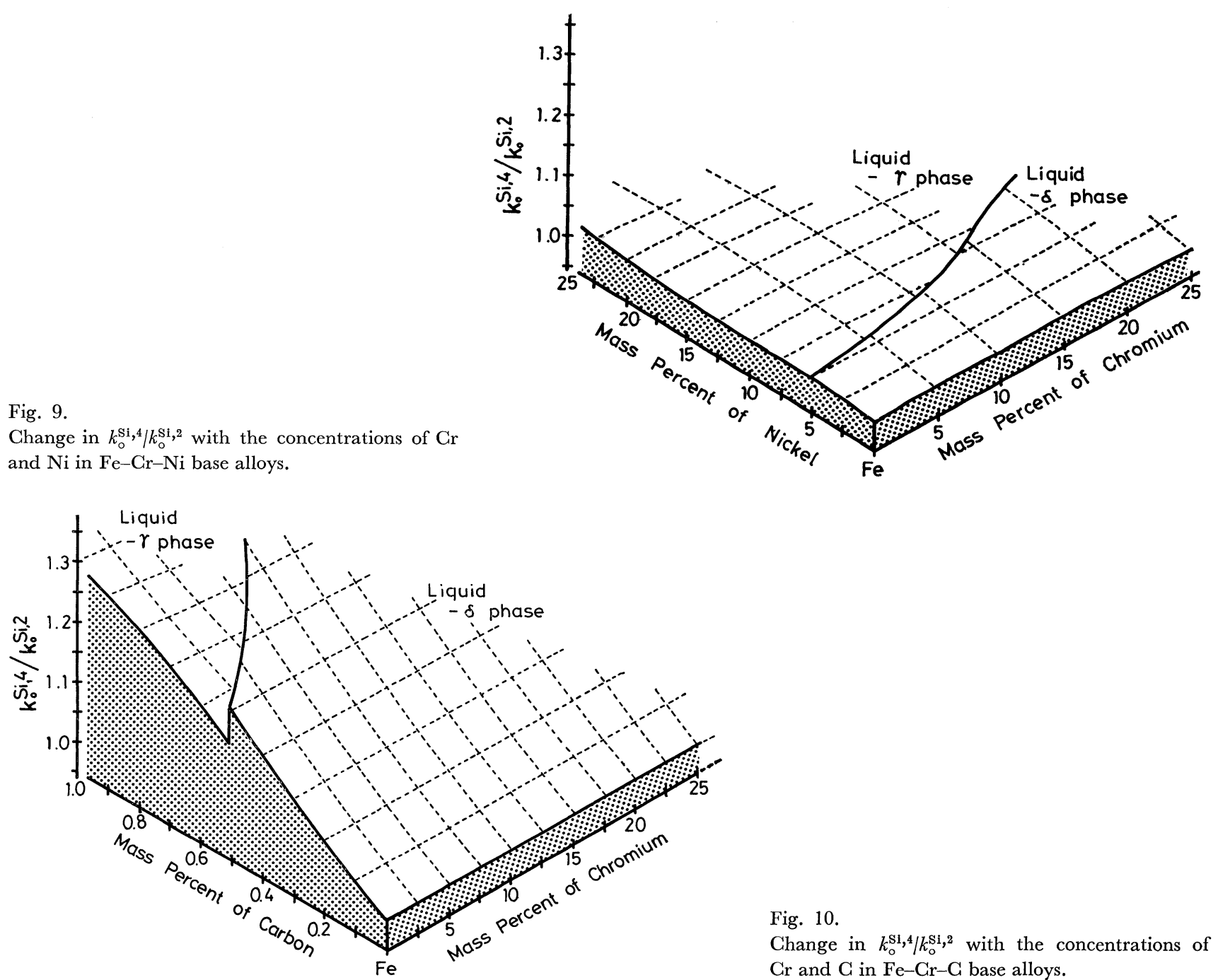

Fig. 10.

Change in $k_{\circ}^{\mathrm{Si}, 4} / k_{\circ}^{\mathrm{Si}, 2}$ with the concentrations of $\mathrm{Cr}$ and $\mathrm{C}$ in $\mathrm{Fe}-\mathrm{Cr}-\mathrm{G}$ base alloys.

the concentration of carbon in $\mathrm{Fe}-\mathrm{Cr}-\mathrm{C}$ base alloys is large as can be seen from Fig. 10. Thus, the influence of carbon on $k_{\circ}^{x}$ can not be ignored in $\mathrm{Fe}-\mathrm{C}$ base alloys. Consequently, DIP and DIC are considered to be useful for the evaluation of the effects of solute-interactions on $k_{\circ}^{X}$ in multi-component iron alloys.

The advantage of the application of DIP is the simplicity for the evaluation of the effect of solute-interaction on $k_{\circ}^{x}$ in multi-component iron alloys. On the other hand, since the interaction parameter $\varepsilon_{x}^{Y}$, which is generally defined for an infinitely dilute solution, is used for DIP, some problems may occur for the application of DIP in the higher concentration region of $\mathrm{Cr}$ and $\mathrm{Ni}$ in $\mathrm{Fe}-\mathrm{Cr}-\mathrm{Ni}$ base alloys. Then, $k_{\mathrm{o}}^{X}$ in these multi-component iron alloys was calculated by the use of the computer calculation technique recently developed for the phase diagram. ${ }^{19,21,22)}$ In this case, as the information on the excess free energy $G^{E x}$ of each phase in multi-component iron alloys has not been obtained thoroughly, it is necessary to determine $G^{E x}$ of each phase by combining the interaction energy of each binary system which constitutes the multi-component iron alloys. Although several equations ${ }^{23,24)}$ have been proposed to approximate the excess free energy in multi-component iron alloys, the simplest equation ${ }^{24)}$ shown in Eq. (11) was adopted in this work. This approximation is the simple sum of the excess free energy of each binary system proposed by Kaufman and Nesor. ${ }^{25)}$

$$
G^{E x}=\sum \mathcal{N}_{i} \mathcal{N}_{j}\left(\mathcal{N}_{i} g_{i j}+\mathcal{N}_{j} h_{i j}\right)
$$

where, $g_{i j}, h_{i j}$ : interaction parameter between $i$ and $j$ elements, respectively.

The values of $g_{i j}$ and $h_{i j}$ are shown in Table 4.26-31) As some of the values of $g_{i j}$ and $h_{i j}$ in bcc or fcc phase were not available, the same values in the other solid phase were used for the calculation. The data on free energy of fusion of pure elements are indicated in Table 5. ${ }^{27,28,30,31)}$ The calculated results of $k_{\circ}^{x}$ were shown in Table 6. As can be seen from this table, the calculated results almost agree with the experimental ones, but on the whole the former shows smaller values than the latter except $k_{\circ}^{\text {cr }}$ and $k_{\circ}^{\text {si }}$ in equilibrium of liquid and $\delta$ phases. Consequently, for the more strict discussion on $k_{\circ}^{x}$ in multi-component alloys, it is necessary to derive the appropriate equation for the excess free energy in those alloys and also to take into account a new interaction parameter.

\section{Summary}

In this work, the equilibrium distribution of solute 
Table 4. Values of $g_{i j}$ and $h_{i j}\left(\mathrm{~J} \cdot \mathrm{mol}^{-1}\right)$.

The upper values are $g_{i j}$ and the lower ones $h_{i j}$ for each phase.

The values with $*$ indicate the same data of the other solid phase.

\begin{tabular}{|c|c|c|c|c|}
\hline$i-j$ & liquid & bcc & $\mathrm{fcc}$ & Ref. No. \\
\hline $\mathrm{Fe}-\mathrm{Cr}$ & $\begin{array}{l}20794-10.46 \cdot T \\
20794-10.46 \cdot T\end{array}$ & $\begin{array}{l}25104-10.46 \cdot T \\
25104-10.46 \cdot T\end{array}$ & $\begin{array}{l}7405-6.276 \cdot T \\
7405-6.276 \cdot T\end{array}$ & 27) \\
\hline $\mathrm{Fe}-\mathrm{Ni}$ & $\begin{array}{l}-8368+2.72 \cdot T \\
-32217+9.205 \cdot T\end{array}$ & $\begin{array}{l}1339+1.3275 \cdot 10^{-3} \cdot T^{2} \\
-1.587 \cdot 10^{-6} \cdot T^{3} \\
-16276+3.5412 \cdot 10^{-2} \cdot T^{2} \\
-1.3191 \cdot 10^{-5} \cdot T^{3}\end{array}$ & $\begin{array}{l}2092-3.8314 \cdot 10^{-3} \cdot T^{2} \\
+1.6338 \cdot 10^{-6} \cdot T^{3} \\
-34881+2.4404 \cdot 10^{-2} \cdot T^{2} \\
-1.0401 \cdot 10^{-5} \cdot T^{3}\end{array}$ & 27) \\
\hline $\mathrm{Fe}-\mathrm{Si}$ & $\begin{array}{l}-173636+38.49 \cdot T \\
-108366+17.57 \cdot T\end{array}$ & $\begin{array}{l}-129704+7.95 \cdot T \\
-297064+136.82 \cdot T\end{array}$ & $\begin{array}{l}-136817+7.95 \cdot T \\
-304177+136.82 \cdot T\end{array}$ & 31) \\
\hline $\mathrm{Fe}-\mathrm{Mn}$ & $\begin{array}{l}-19874+16.987 \cdot T \\
-21589+16.987 \cdot T\end{array}$ & $\begin{array}{l}4100+4.686 \cdot T \\
5188+1.506 \cdot T\end{array}$ & $\begin{array}{l}-18870+16.987 \cdot T \\
-18870+16.987 \cdot T\end{array}$ & 30) \\
\hline $\mathrm{Fe}-\mathrm{Mo}$ & $\begin{array}{r}0 \\
17573 \\
\end{array}$ & $\begin{array}{c}32217-8.368 \cdot T \\
33422\end{array}$ & $\begin{array}{c}24790-8.368 \cdot T \\
25376\end{array}$ & 28) \\
\hline $\mathrm{Cr}-\mathrm{Ni}$ & $\begin{array}{l}-8368 \\
-8368\end{array}$ & $\begin{array}{r}53555.2-27.196 . T \\
-13388.8-2.092 \cdot T\end{array}$ & $\begin{array}{l}-8368+0.4696 \cdot 10^{-2} \cdot T^{2} \\
-0.78027 \cdot 10^{-5} \cdot T^{3} \\
-25104+0.94772 \cdot 10^{-2} \cdot T^{2} \\
-2.60715 \cdot 10^{-6} \cdot T^{3}\end{array}$ & 27) \\
\hline $\mathrm{Cr}-\mathrm{Si}$ & $\begin{array}{r}-87864-33.472 \cdot T \\
-112968+33.472 \cdot T \\
\end{array}$ & $\begin{array}{r}-81588-37.656 \cdot T \\
-106692+29.288 \cdot T \\
\end{array}$ & $\begin{array}{l}-81588-37.656 \cdot T^{*} \\
-106692+29.288 \cdot T^{*}\end{array}$ & 31) \\
\hline $\mathrm{Cr}-\mathrm{Mn}$ & $\begin{array}{l}-12552+10.46 \cdot T \\
-12552+10.46 \cdot T\end{array}$ & $\begin{array}{l}-8786+10.46 \cdot T \\
-8786+10.46 \cdot T \\
\end{array}$ & $\begin{array}{l}-17573+10.46 \cdot T \\
-17573+10.46 \cdot T\end{array}$ & 30) \\
\hline $\mathrm{Cr}-\mathrm{Mo}$ & $\begin{array}{l}25522-11.30 \cdot T \\
12552-5.86 \cdot T\end{array}$ & $\begin{array}{l}34309-11.30 \cdot T \\
21338-5.86 \cdot T\end{array}$ & $\begin{array}{l}34309-11.30 \cdot \mathcal{T}^{*} \\
21338-5.86 \cdot \mathcal{T}^{*}\end{array}$ & 28) \\
\hline $\mathrm{Ni}-\mathrm{Si}$ & $\begin{array}{l}-259994+62.01 \cdot T \\
-133888+22.01 \cdot T\end{array}$ & $\begin{array}{l}-264345+62.01 \cdot T^{*} \\
-138239+22.01 \cdot T^{*}\end{array}$ & $\begin{array}{l}-264345+62.01 \cdot T \\
-138239+22.01 \cdot T\end{array}$ & 31) \\
\hline $\mathrm{Ni}-\mathrm{Mn}$ & $\begin{array}{l}-76986+10.878 \cdot T \\
-64434+10.878 \cdot T \\
\end{array}$ & $\begin{array}{l}-58158+3.64 \cdot T \\
-45606+3.64 \cdot T\end{array}$ & $\begin{array}{l}-64434+10.878 \cdot T \\
-51882+10.878 \cdot T\end{array}$ & 30) \\
\hline $\mathrm{Ni}-\mathrm{Mo}$ & $\begin{array}{l}-17573+13.807 \cdot T \\
-17573+13.807 \cdot T \\
\end{array}$ & $\begin{array}{l}23430+13.807 \cdot T \\
23430+13.807 \cdot T\end{array}$ & $\begin{array}{l}-13598+13.807 \cdot T \\
-13598+13.807 \cdot T\end{array}$ & 29) \\
\hline $\mathrm{Si}-\mathrm{Mn}$ & $\begin{array}{r}-81170+2.092 \cdot T \\
-101253-23.012 \cdot T \\
\end{array}$ & $\begin{array}{l}-72802+2.092 \cdot T \\
-92885-23.012 \cdot T\end{array}$ & $\begin{array}{c}-84098+2.092 \cdot T \\
-104184-23.012 \cdot T \\
\end{array}$ & 31) \\
\hline $\mathrm{Si}-\mathrm{Mo}$ & $\begin{array}{l}-83680 \\
-83680\end{array}$ & $\begin{array}{l}-61923 \\
-61923\end{array}$ & $\begin{array}{l}-61923^{*} \\
-61923^{*} \\
\end{array}$ & 31) \\
\hline $\mathrm{Mn}-\mathrm{Mo}$ & $\begin{array}{l}0 \\
0\end{array}$ & $\begin{array}{l}0 \\
0\end{array}$ & $\begin{array}{l}0 \\
0\end{array}$ & 26) \\
\hline
\end{tabular}

Table 5. Data on free energy of fusion of pure elements. $\left(\mathrm{J} \cdot \mathrm{mol}^{-1}\right)$

\begin{tabular}{|c|c|c|}
\hline $\mathrm{Fe}$ & $\begin{array}{l}\dot{\mu}^{L}-\dot{\mu}^{\mathrm{bcc}}=13807.2-7.6316 \cdot T \\
\dot{\mu}^{L}-\dot{\mu}^{\mathrm{fec}}=14744.416-8.1965 \cdot T\end{array}$ & $27)^{*}$ \\
\hline $\mathrm{Cr}$ & $\begin{array}{l}\dot{\mu}^{L}-\dot{\mu}^{\mathrm{bcc}}=18200-8.368 \cdot T \\
\dot{\mu}^{L}-\dot{\mu}^{\mathrm{fcc}}=7740.4-8.9956 \cdot T\end{array}$ & $27)^{*}$ \\
\hline $\mathrm{Ni}$ & $\begin{array}{l}\dot{\mu}^{L}-\dot{\mu}^{\mathrm{bcc}}=12049.92-9.163 \cdot T \\
\dot{\mu}^{L}-\dot{\mu}^{\mathrm{fcc}}=17614.64-10.209 \cdot T\end{array}$ & $27) *$ \\
\hline $\mathrm{Si}$ & $\begin{array}{l}\dot{\mu}^{L}-\dot{\mu}^{\mathrm{bcc}}=6276-10.46 \cdot T \\
\dot{\mu}^{L}-\dot{\mu}^{\mathrm{fcc}}=0-12.13 \cdot T\end{array}$ & $31)^{*}$ \\
\hline $\mathrm{Mn}$ & $\begin{array}{l}\dot{\mu}^{L}-\dot{\mu}^{\mathrm{bcc}}=14644-9.623 \cdot T \\
\dot{\mu}^{L}-\dot{\mu}^{\mathrm{fcc}}=16401-10.878 \cdot T\end{array}$ & $30) *$ \\
\hline Mo & $\begin{array}{l}\dot{\mu}^{L}-\dot{\mu}^{\mathrm{bcc}}=24267-8.368 \cdot T \\
\dot{\mu}^{L}-\dot{\mu}^{\mathrm{fcc}}=13807-8.996 \cdot T\end{array}$ & $28)^{*}$ \\
\hline
\end{tabular}

* Reference number. elements between solid and liquid phases in multicomponent iron alloys were discussed thermodynamically. Furthermore, the equilibrium distribution coefficients $k_{0}^{X}$ of some elements in $\mathrm{Fe}-\mathrm{Cr}-\mathrm{Ni}$ base alloys were determined experimentally and also thermodynamically.

The results obtained are summarized as follows.

(1) In order to evaluate the effects of solute-interactions on the equilibrium distribution of solute $X$ in multi-component iron alloys, a new thermodynamic parameter was introduced and this was defined as Distribution Interaction Parameter (DIP) $\delta_{X}^{Y}$.

$$
\delta_{X}^{Y}=\left(1-m k_{\circ}^{Y, M}\right) \varepsilon_{X}^{Y, L}
$$

The effect of solute element $Y$ on $k_{\mathrm{o}}^{X, M}$ in multicomponent iron alloys could be determined by the sign and the absolute value of the parameter $\delta_{X}^{Y}$. 
Table 6. Calculated results on the equilibrium distribution coefficients $k_{0}^{X}$ of $\mathrm{Cr}, \mathrm{Ni}, \mathrm{Si}, \mathrm{Mn}$ and $\mathrm{Mo}$ in $\mathrm{Fe}-\mathrm{Cr}-\mathrm{Ni}$ base alloys.

\begin{tabular}{|c|c|c|c|c|c|c|c|c|c|c|}
\hline & \multicolumn{5}{|c|}{ Compositions (mass\%) } & \multicolumn{5}{|c|}{$k_{\circ}^{X}$} \\
\hline & Cr & $\mathrm{Ni}$ & $\mathrm{Si}$ & $\mathrm{Mn}$ & Mo & $\mathrm{Cr}$ & $\mathrm{Ni}$ & $\mathrm{Si}$ & $\mathrm{Mn}$ & Mo \\
\hline \multirow{4}{*}{ Liquid- $\delta$} & 3.0 & 3.0 & 0.5 & 0.5 & 0.5 & $0.97(0.94)$ & $0.68(0.80)$ & $0.94(0.79)$ & $0.75(0.81)$ & $0.68(0.85)$ \\
\hline & 5.0 & 1.5 & 0.5 & 0.5 & 0.5 & $0.97(0.96)$ & $0.73(0.78)$ & $0.88(0.79)$ & 0.77 & 0.71 \\
\hline & 5.0 & 5.0 & 0.5 & 0.5 & 0.5 & $0.99(0.95)$ & $0.64(0.79)$ & $0.97(0.76)$ & $0.75(0.76)$ & $0.74(0.80)$ \\
\hline & 10.0 & 5.0 & 0.5 & 0.5 & 0.5 & $1.03(0.97)$ & $0.67(0.78)$ & $0.88(0.80)$ & 0.80 & 0.87 \\
\hline \multirow{7}{*}{ Liquid- $\gamma$} & 5.0 & 10.0 & 0.5 & 0.5 & 0.5 & $0.83(0.94)$ & $0.85(0.92)$ & $0.72(0.72)$ & $0.77(0.83)$ & $0.52(0.71)$ \\
\hline & 5.0 & 15.0 & 0.5 & 0.5 & 0.5 & $0.83(0.94)$ & $0.88(0.92)$ & $0.66(0.69)$ & $0.78(0.76)$ & $0.56(0.67)$ \\
\hline & 10.0 & 10.0 & 0.5 & 0.5 & 0.5 & $0.82(0.95)$ & $0.86(0.93)$ & $0.68(0.74)$ & $0.75(0.80)$ & $0.53(0.63)$ \\
\hline & 10.0 & 25.0 & 0.5 & 0.5 & 0.5 & $0.83(0.96)$ & $0.94(0.94)$ & $0.48(0.61)$ & $0.79(0.72)$ & $0.65(0.68)$ \\
\hline & 10.0 & 40.0 & 0.5 & 0.5 & 0.5 & $0.83(0.97)$ & $0.99(0.96)$ & $0.36(0.57)$ & $0.79(0.66)$ & $0.75(0.75)$ \\
\hline & 20.0 & 25.0 & 0.5 & 0.5 & 0.5 & $0.82(0.97)$ & $0.97(0.95)$ & $0.30(0.69)$ & $0.79(0.90)$ & $0.75(0.67)$ \\
\hline & 20.0 & 40.0 & 0.5 & 0.5 & 0.5 & $0.86(0.97)$ & $1.02(0.98)$ & $0.30(0.57)$ & $0.79(0.74)$ & $0.75(0.71)$ \\
\hline
\end{tabular}

The values in parentheses show the experimental results.

(2) By means of DIP, it is possible to evaluate easily the effect of carbon on $k_{o}^{x}$ of several elements in $\mathrm{Fe}-\mathrm{C}$ base alloys.

(3) Small dependence of $k_{\mathrm{o}}^{x}$ of $\mathrm{Cr}, \mathrm{Ni}, \mathrm{Si}, \mathrm{Mn}$ and $\mathrm{Mo}$ on the concentrations of $\mathrm{Cr}$ and $\mathrm{Ni}$ in $\mathrm{Fe}-$ $\mathrm{Gr}-\mathrm{Ni}$ base alloys was found experimentally and those results were explained by the application of DIP.

\section{REFERENCES}

1) Z. Morita and T. Tanaka: Trans. Iron Steel Inst. Jpn., 23 (1983), 824.

2) Z. Morita and T. Tanaka: Trans. Iron Steel Inst. Jpn., 24 (1984), 206.

3) T. Umeda, Y. Kimura, M. Suzuki and T. Ogata: Proceedings of the 4th Japan-Germany Seminar on Basic Principles of Solidification of Steel with Special Regard to Continuous Casting, ISIJ, Tokyo, (1980), 106.

4) A. Kagawa, S. Moriyama and T. Okamoto: J. Mater. Sci., 17 (1982), 135.

5) A. Kagawa and T. Okamoto: Met. Sci., 14 (1980), 519.

6) A. Kagawa, K. Iwata, A. A. Nofal and T. Okamoto: Mater. Sci. Technol., 1 (1985), 678.

7) A.J.W. Ogilvy, A. Ostrouskii and D. H. Kirkwood: Met. Sci., 15 (1981), 168.

8) Z. Morita and T. Tanaka: Tetsu-to-Hagané, 69 (1983), S1023.

9) J. Chipman: Basic Open Hearth Steelmaking, ed. by Physical Chemistry of Steel-making Comm. AIME, New York, (1951), 644.

10) Y. Ueshima, N. Komatsu, S. Mizoguchi and H. Kajioka: Tetsu-to-Hagané, 73 (1987), 1551.

11) "Selected Equilibrium Values for Steelmaking Reactions", The 19th Comm. (Steelmaking), The Japan Soc. for the Promotion of Science, Rep. No. 19-10588, (Nov., 1984); Steelmaking Data Source Book, de. by Y. Matsushita and
H. Sakao, Gordon \& Bleach, New York, (1988).

12) T. Okamoto, Z. Morita, A. Kagawa and T. Tanaka: Trans. Iron Steel Inst. Jpn., 23 (1983), 266.

13) A. Yamada, T. Umeda, M. Suzuki, G. Aragane, H. Kihara and Y. Kimura: Tetsu-to-Hagané, 73 (1987), 1676.

14) U. Siegel and A. Haas: Neue Hütte, 29 (1984), 211.

15) E. Schürmann and J. Brauckmann: Arch. Eisenhüttenwes., 48 (1977), 3.

16) J. Heritier and J. Levy: Scr. Metall., 10 (1976), 107.

17) T. Okamoto, K. Kishitake and K. Murakami: Trans. Iron Steel Inst. Jpn., 21 (1981), 641.

18) E. Schürmann and H. J. Voss: Arch. Eisenhüttenwes., 48 (1977), 129.

19) A. Yamada, T. Umeda and Y. Kimura: 10th JapanUSSR Joint Symposium on Physical Chemistry of Metallurgical Processes, ISIJ, Tokyo, (1985), Paper No. 16.

20) D. M. Kundrat, M. Chochol and J. F. Elliott: Metall. Trans. B, 15B (1984), 663.

21) L. Kaufman and H. Bernstein: Computer Calculation of Phase Diagrams, Academic Press, New York, (1970).

22) T. Nishizawa and M. Hasebe: Tetsu-to-Hagané, 67 (1981), 1887, 2086.

23) I. Arpshofen, M. J. Pool, F. Sommer, U. Gerling, B. Predel and E. Schultheiss: Z. Metallkde., 74 (1983), 25.

24) G.H.P. Lupis: Chemical Thermodynamics of Materials, North-Holland, New York, (1983).

25) L. Kaufman and H. Nesor: Z. Metallkde., 64 (1973), 249.

26) L. Kaufman and H. Nesor: Annual Review of Materials Science, III, R. A. Huggins, ed., Palo Alto, California, (1973).

27) L. Kaufman: CALPHAD, 1 (1977), 7.

28) L. Kaufman and H. Nesor: CALPHAD, 2 (1978), 55.

29) L. Kaufman and H. Nesor: CALPHAD, 2 (1978), 81.

30) L. Kaufman: CALPHAD, 2 (1978), 117.

31) L. Kaufman: CALPHAD, 3 (1979), 45. 